\title{
Mayombensin, a New Azadirachtin I Derivative with Unusual Structure from Guarea mayombensis
}

(®) $\odot \Theta$

\author{
Authors \\ Charlie Djeukeu', Michel Feussi Tala², Carine Mvot Akak¹, Anatole Guy Blaise Azebaze¹, Alain Francois Kamdem Wafo', \\ Jean Duplex Wansi ${ }^{1}$, Juliette Catherine Vardamides ${ }^{1}$, Hartmut Laatsch ${ }^{2}$
}

\author{
Affiliations \\ 1 Faculty of Science, Department of Chemistry, University \\ of Douala, Douala, Cameroon \\ 2 University of Göttingen, Institute of Organic and \\ Biomolecular Chemistry, Göttingen, Germany
}

Key words

Guarea mayombensis, Meliaceae, tetranortriterpenoid, mayombensin, azadirachtin homologue

received 18.02 .2017

revised $\quad 07.06 .2017$

accepted 08.09.2017

Bibliography

DOI https://doi.org/10.1055/s-0043-120070

Planta Med Int Open 2017; 4: e104-e107

(c) Georg Thieme Verlag KG Stuttgart - New York

ISSN 2509-9264

Correspondence

Pr. Vardamides Juliette Catherine

Faculty of Science

Department of Chemistry

\author{
University of Douala \\ P.O. Box 24157 \\ Douala 24157 \\ Cameroon \\ Tel.: + (237)677919603, Fax: + (237)33404291 \\ jucathmas@yahoo.fr
}

Supporting information available online at http://www.

thieme-connect.de/products

\begin{abstract}
A new highly oxidized tetranortriterpenoid, named mayombensin (1), was isolated from the twigs of Guarea mayombensis together with five known compounds and, further, two ceramides, 3,4-dimethyl-secotirucalla-4(28),7,24trien-3,21-dioic acid (3), the glucosides of stigmasterol and $\beta$-sitosterol, and the respective aglyca. The structure of $\mathbf{1}$ was elucidated by detailed NMR analysis and confirmed as a novel azadirachtin homologue.
\end{abstract}

\section{Introduction}

The genus Guarea belongs to the family Meliaceae and has 150 species of trees and shrubs in tropical America (8 of them occur in Panama [1] and 20 in Africa [2]). Some species are used in folk medicine for the treatment of rheumatism and as an emetic and hemostatic remedy [3]. A few pharmacological studies demonstrated anti-inflammatory, antiviral, and antiprotozoal activities of some Guarea extracts [3-6]. Previous phytochemical investigations on this genus led to the isolation and identification of a wide variety of constituents including sesqui-, di-, and triterpenes, limonoids, steroids, flavonoids, and coumarins [3,7-10]. Although a high number of chemical studies on the genus Guarea have been reported, none is known on Guarea mayombensis Pellegr., which is a big tree up to 10-15 m high, commonly distributed in tropical Africa. This paper deals with the structure elucidation of a new tetranortriterpenoid $\mathbf{1}$ isolated together with five known compounds and, further, two ceramides from the methanol extract of the finely powdered twigs of $G$. mayombensis on chromatographic separation.

\section{Results and Discussion}

ESI HRMS of compound 1 displayed a pseudo-molecular ion peak at $\mathrm{m} / \mathrm{z} 593.2583\left([\mathrm{M}-\mathrm{H}]^{-}\right)$, consistent with the molecular formula $\mathrm{C}_{30} \mathrm{H}_{42} \mathrm{O}_{12}$. Its IR spectrum exhibited typical absorptions for hydroxy $\left(3423 \mathrm{~cm}^{-1}\right)$, ester carbonyl $\left(1697 \mathrm{~cm}^{-1}\right)$, ether $(1268,1142$, $\left.1075 \mathrm{~cm}^{-1}\right)$, and double bond $\left(1652 \mathrm{~cm}^{-1}\right)$ functionalities. The UV spectrum showed a peak at $220 \mathrm{~nm}$ due to the $\pi-\pi{ }^{*}$ transition of an $\alpha, \beta$-unsaturated carbonyl group $[8,11]$. The ${ }^{13} \mathrm{C}$ NMR spectrum of 1 provided evidence for a conjugated ester carbonyl group by signals at $\delta_{C}=167.6$ (C-1') and of two olefinic carbon atoms at $\delta_{C}=137.8$ (C-3') and 130.1 (C-2'). The ${ }^{13}$ C NMR spectrum displayed a further 27 signals of aliphatic carbons, of which 14 between 
$\delta_{C}=60-101$ were oxygenated. This agreed well with the ${ }^{1} \mathrm{H}$ NMR spectrum ( $\vee$ Table 1 ), which exhibited a set of signals attributable to oxymethine and oxymethylene groups between $\delta_{H}=3.50-6.50$. Besides, the ${ }^{1} \mathrm{H}$ NMR and $\mathrm{HSQC}$ spectra also showed three aliphatic methyl singlets of $\mathrm{H}_{3}-18, \mathrm{H}_{3}-29$, and $\mathrm{H}_{3}-30$, and two broadened signals of olefinic methyls, which coupled with an olefinic proton at $\delta_{H^{\prime}}=7.34\left(\mathrm{H}^{-} 3^{\prime}\right)$. In the HMBC experiment, cross-peaks from both $\mathrm{H}-3$ ' and $\mathrm{H}_{3}-5^{\prime}$ to $\mathrm{C}-1^{\prime}$ and $\mathrm{C}-2$ ', and from $\mathrm{H}_{3}-4$ ' to $\mathrm{C}-2$ ' were observed, indicating the presence of a tigloyl unit. The above data suggested 1 to be a highly oxygenated nortriterpene, structurally related to azadirachtin-type limonoids [12-14].

In particular, the NMR data of C-5-C-10 and C-13-C-18 for $\mathbf{1}$ were very similar to those of azadirachtin I (2) [12], suggesting that these two compounds were structurally related. This was supported by detailed analysis of the 2D NMR data (HSQC, HMBC). The COSY and TOCSY spectra clearly defined the spin system of $\mathrm{H}-1$ / $\mathrm{H}_{2}-2 / \mathrm{H}-3, \mathrm{H}-5 / \mathrm{H}-6 / \mathrm{H}-7$, and $\mathrm{H}-15 / \mathrm{H}_{2}-16 / \mathrm{H}-17$. Furthermore, the $\mathrm{HMBC}$ spectrum showed correlations from $\mathrm{H}-1$ to $\mathrm{C}-3, \mathrm{C}-5, \mathrm{C} 10$, C-19 and C-1', from $\mathrm{H}-3$ to $\mathrm{C}-5$, from $\mathrm{H}-5$ to $\mathrm{C}-3, \mathrm{C}-4, \mathrm{C}-6, \mathrm{C}-7, \mathrm{C}-10$, $\mathrm{C}-19, \mathrm{C}-28$, and $\mathrm{C}-29$, from $\mathrm{H}-7$ to $\mathrm{C}-5, \mathrm{C}-6, \mathrm{C}-8, \mathrm{C}-9, \mathrm{C}-14$, and $\mathrm{C}-30$, from $\mathrm{H}_{2}-28$ to $\mathrm{C}-3, \mathrm{C}-4, \mathrm{C}-6$, and $\mathrm{C}-29$, and from $\mathrm{H}_{3}-29$ to $\mathrm{C}-3$, $\mathrm{C}-4, \mathrm{C}-5$, and $\mathrm{C}-28$, confirming the carbon skeleton and the substitution in rings $A$ and $B$.

Further comparison of the NMR data has shown that compound 1 differed from azadirachtin I (2) by the replacement of the acetyl group in the C-3 position by a hydroxy group, and of the tetrahy-

- Table $1{ }^{1} \mathrm{H}(600 \mathrm{MHz})$ and ${ }^{13} \mathrm{C}(125 \mathrm{MHz})$ NMR data of mayombensin (1) in pyridine- $d_{5}$ with HMBC assignments.

\begin{tabular}{|c|c|c|c|}
\hline Position & $\delta_{\mathrm{H}}(\mathrm{m}, \boldsymbol{J}$ in $\mathrm{Hz})$ & $\delta_{c}$ & Complete list of $\mathrm{HMBC}(\mathrm{H} \rightarrow \mathrm{C})$ correlations \\
\hline 1 & $6.01(\mathrm{t}, 2.8)$ & 75.4 & $C-3,5,10,19(w), 1^{\prime}(w)$ \\
\hline $2 \alpha$ & $2.70(\mathrm{td}, 2.3,15.0)$ & 32.6 & $C-3,4,10$ \\
\hline $2 \beta$ & $2.27(\mathrm{td}, 2.9,15.8)$ & & \\
\hline 3 & 4.06 (brs) & 70.8 & $C-5$ \\
\hline 4 & - & 44.8 & - \\
\hline 5 & $4.16(d, 12.6)$ & 35.2 & $\mathrm{C}-3,4,6,7,10,19,28,29$ \\
\hline 6 & $3.97(\mathrm{~m})$ & 75.6 & C-7 (vw), $8(\mathrm{vw})$ \\
\hline 7 & 4.96 (brs) & 74.5 & $C-5,6,8,9,14,30$ \\
\hline 8 & - & 46.0 & - \\
\hline 9 & 3.47 (brs) & 50.6 & $\mathrm{C}-1,8,10,13(\mathrm{w}), 14,19,30$ \\
\hline 10 & - & 49.9 & - \\
\hline 11 & 6.11 (brs) & 101.9 & $C-8,10,19$ \\
\hline 13 & - & 66.8 & - \\
\hline 14 & - & 70.6 & - \\
\hline 15 & 4.96 (brs) & 79.6 & $\mathrm{C}-13,14,17,21$ \\
\hline $16 a$ & 2.22 (brd, 11.1) & 28.1 & $\mathrm{C}-13,14,15,17,20$ \\
\hline $16 b$ & 1.81 (ddd, 11.6, 5.5, 2.9) & & $C-20(w)$ \\
\hline 17 & $2.66(d, 5.3)$ & 53.9 & $\mathrm{C}-13,14,15,16(w), 18(w), 20,21$ \\
\hline 18 & $2.38(\mathrm{~s})$ & 18.7 & $C-13,14,17$ \\
\hline 19 & $4.22(\mathrm{~d}, 2.9)$ & 72.3 & $C-1,5,10,11$ \\
\hline 20 & - & 93.1 & - \\
\hline 21 & $6.54(\mathrm{~s})$ & 95.0 & $C-20,22$ \\
\hline $22 \alpha$ & $4.34(\mathrm{~m})$ & 59.5 & $\mathrm{C}-23(\mathrm{vw})$ \\
\hline $22 \beta$ & $3.48(\mathrm{dd}, 11.4,2.0)$ & & C-21 \\
\hline $23 \alpha$ & $3.57(\mathrm{dd}, 11.3,2.3)$ & 60.0 & C-20 \\
\hline $23 \beta$ & $4.56(\mathrm{td}, 11.7,2.7)$ & & C-22 \\
\hline $28 \alpha$ & $4.67(d, 7.2)$ & 77.9 & $C-3,4,6,29$ \\
\hline $28 \beta$ & $3.75(d, 7.2)$ & & $C-4(w), 5,6,29$ \\
\hline 29 & $1.02(\mathrm{~s})$ & 20.5 & $C-3,4,5,28$ \\
\hline 30 & $1.55(\mathrm{~s})$ & 22.7 & $C-7,8,9,14$ \\
\hline 1 ' & - & 167.6 & - \\
\hline $2^{\prime}$ & - & 130.1 & - \\
\hline $3^{\prime}$ & $7.33(\mathrm{dq}, 1.4,7.1)$ & 137.8 & $C-1^{\prime}, 2^{\prime}, 4^{\prime}, 5^{\prime}$ \\
\hline 4' & $1.48(\mathrm{dd}, 7.1,1.3)$ & 14.7 & $C-2^{\prime}, 3^{\prime}$ \\
\hline $5^{\prime}$ & 1.83 (brs) & 12.8 & C-1', 2', 3' \\
\hline $\mathrm{OH}$ & $6.55,5.78,5.69(3 \mathrm{~s} \mathrm{br})$ & - & \\
\hline
\end{tabular}


drofuran ring at C-20,21 by a 1,4-dioxan moiety. The latter was derived from the ${ }^{1} \mathrm{H}$ and ${ }^{13} \mathrm{C}$ NMR spectra of 1 by the presence of two oxymethylene groups at $\delta_{H}=4.38 / 3.52\left(\delta_{C}=59.5, C-22\right)$ and $\delta_{H}=4.60 / 3.61\left(\delta_{C} 60.0, C-23\right)$, which formed an isolated spin system in the ${ }^{1} \mathrm{H}-{ }^{1} \mathrm{H}$ TOCSY experiment. Moreover, the HMBC spectrum of 1 ( $>$ Fig. 1) gave important correlations between $\mathrm{H}_{\beta}-22$ and an acetal-methine at $\delta_{C}=95.0(C-21)$, between $\mathrm{H}_{\alpha}-23$ and a quaternary acetal carbon at $\delta_{C}=93.1(C-20)$, and between $\mathrm{H}-21$ with both $\mathrm{C}-20$ and $\mathrm{C}-22$. Therefore, the planar structure of compound 1 was characterized as 3-deacetyl-20,21-defuranyl-20,21dioxanyl azadirachtin I and named mayombensin.

The relative configuration of mayombensin (1) was established on the basis of NOESY analysis and comparison with data reported in the literature for related compounds [11, 14]. Accordingly, C-11, $\mathrm{C}-19$, and $\mathrm{C}-30$ were assigned as $\beta$, and $\mathrm{H}-5$ was $\alpha$-oriented based on the biosynthesis of azadirachtin-type limonoids [15]. The NOESY spectrum of 1 showed correlations from both $\mathrm{H}-5$ and $\mathrm{H}-1$ to $\mathrm{H}-9$.

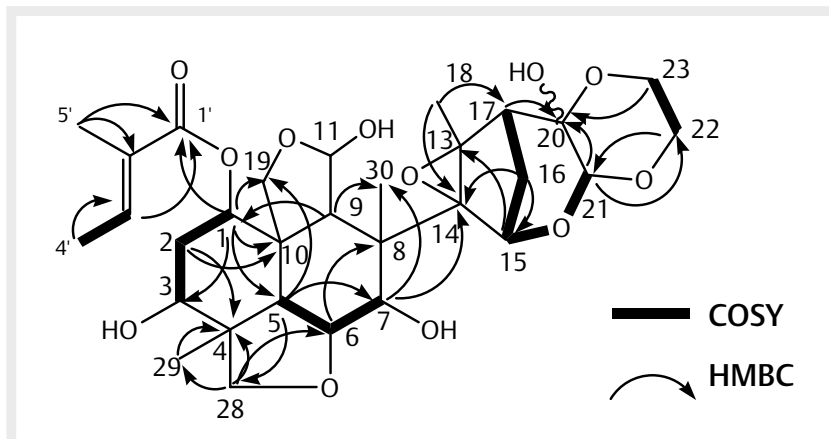

- Fig. 1 Selected COSY and HMBC correlations of mayombensin (1).
Further NOESY correlations from $\mathrm{H}-9$ to $\mathrm{H}_{3}-18$, from $\mathrm{H}_{3}-18$ to $\mathrm{H}-17$ and $\mathrm{H}-21$, and from $\mathrm{H}-21$ to $\mathrm{H}-15$ were observed. The same experiment also exhibited correlations between $\mathrm{H}_{3}-30 / \mathrm{H}-7, \mathrm{H}_{3}-30 / \mathrm{H}-6$, $\mathrm{H}-6 / \mathrm{H}_{3}-29$, and $\mathrm{H}_{3}-29 / \mathrm{H}-3$. The relative configuration of mayombensin (1) was thus defined as shown in $>$ Fig. 2, which agrees - with exception for C-11,20 - with all other azadirachtins.

The known compounds were identified as 3,4-dimethyl-secotirucalla-4(28),7,24-trien-3,21-dioic acid (3), stigmasterol, $\beta$-sitosterol, and the glucosides of the latter two. The structures were determined by comparison of their NMR and mass spectral data with those reported in the literature $[8,16]$. Additionally, two ceramides have been isolated (for data, see Supporting Information).

\section{Materials and Methods}

\section{General procedures}

The optical rotation was measured on a Perkin-Elmer polarimeter 241 at the sodium D line. The IR spectrum was recorded on an FT/ IR-4100 Jasco spectrophotometer. NMR spectra were recorded on Varian Unity $300(300.145 \mathrm{MHz})$ and Varian Inova 500 $(499.876 \mathrm{MHz})$ spectrometers. The NMR data of $\mathbf{1}$ were referenced on pyridine- $d_{5}$ with $\delta_{H} 7.22$ and $\delta_{C} 150.35$; measurements in $\mathrm{CDCl}_{3}$ were referenced to $\delta_{H} 7.24$ and $\delta_{C}$ 77.00. ESI HRMS was measured on a microTOF (Bruker mass spectrometer). Melting points were determined on a Mettler FP61 melting point apparatus. Flash chromatography was performed using silica gel (Macherey Nagel \& Co; 230-400 mesh). Thin-layer chromatography was performed using Merck pre-coated silica gel $60 \mathrm{~F}_{254}$ aluminum foil.

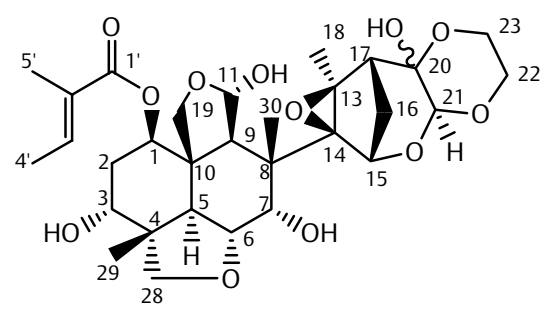

1<smiles>C=C(C)C1CC=C2C(CC[C@@]3(C)C(C(=O)O)[C@@H](CCC=C(C)C)CC[C@@]23C)[C@@]1(C)CCC(=O)O</smiles>

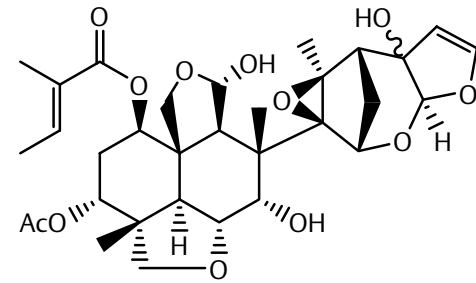

2

Fig. 2 Chemical structures of compounds 1, 2, and 3. 


\section{Plant material}

The twigs of G. mayombensis were collected in December 2014 from Kala Mount, Yaounde Cameroon. Authentication was carried out by M. Victor NANA at the National Herbarium Yaoundé, where a voucher specimen has been deposited (accession number: $46220 \mathrm{HNC}$ ).

\section{Extraction and isolation}

The air-dried powdered twigs of $G$. mayombensis ( $4 \mathrm{~kg}$ ) were extracted with $10 \mathrm{~L}$ of $\mathrm{MeOH}$ at room temperature (twice, each 2 days). After evaporation, $75 \mathrm{~g}$ of extract were obtained. The crude extract was subjected to column chromatography $(100 \times 4.5 \mathrm{~cm})$ over silica gel (70-230 mesh), with a gradient system of $n$-hexaneEtOAc. A total of 370 fractions of ca. $200 \mathrm{~mL}$ each were collected. The pure compounds were obtained by direct crystallization. Fractions 50-67 (2.29g), eluted with $n$-hexane-EtOAc (19:1), gave a mixture of stigmasterol and $\beta$-sitosterol $(36 \mathrm{mg})$. The combined fractions 117-147 (3.9g), eluted with $n$-hexane-EtOAc (17:3), gave 3,4-dimethyl-secotirucalla-4(28),7,24-trien-3,21-dioic acid (3; $32 \mathrm{mg})$. Fractions $228-245(2.21 \mathrm{~g})$, eluted with $n$-hexane-EtOAc (3: 2), afforded ceramide A (8) (18 mg). Fractions 271-285 (1.82 g), eluted with $n$-hexane-EtOAc (1:1) precipitated at room temperature, gave glucosides of stigmasterol and $\beta$-sitosterol $(28 \mathrm{mg})$. The combined fractions $318-326(1.04 \mathrm{~g})$, eluted with $n$-hexane-EtOAc (2:3), afforded mayombensin (1) (18 mg). Combined fractions 335 $358(2.99 \mathrm{~g})$, eluted with $n$-hexane-EtOAc (1:3), yielded ceramide B (9) (8 mg).

Mayombensin (1): White powder; m.p. $209-210^{\circ} \mathrm{C} ;[\alpha]_{D}^{20}+$ 10.4 (c 0.5, MeOH); IR (film): $v_{\max } 3423,2930,1697,1652,1268$, 1142, 1075, $993 \mathrm{~cm}^{-1}$; UV (MeOH): $\lambda_{\max } 220 \mathrm{~nm}(\log \varepsilon=3.81) ;{ }^{1} \mathrm{H}$ and ${ }^{13} \mathrm{C}$ NMR data, see $>$ Table 1; (-)-ESI HRMS: m/z 593.2583 [M - $\mathrm{H}]^{-}$(calcd. for $\mathrm{C}_{30} \mathrm{H}_{42} \mathrm{O}_{12}$ 593.2598).

3,4-Dimethyl-secotirucalla-4(28),7,24-trien-3,21-dioic acid (3): For ${ }^{1} \mathrm{H},{ }^{13} \mathrm{C}$ NMR, and MS data, see Supporting Information.

Ceramide A (8): For ${ }^{1} \mathrm{H},{ }^{13} \mathrm{C}$ NMR, and MS data, see Supporting Information. (+)-ESI HRMS: $\mathrm{m} / \mathrm{z}=704.6138\left([\mathrm{M}+\mathrm{Na}]^{+}\right.$(calcd. for $\mathrm{C}_{42} \mathrm{H}_{83} \mathrm{NNaO}_{5}$ 704.6169). For the formula, see Fig. S1 in the Supporting Information.

Ceramide B (9): For ${ }^{1} \mathrm{H},{ }^{13} \mathrm{C}$ NMR and MS data, see Supporting Information. (+)-ESI HRMS: $\mathrm{m} / \mathrm{z}=720.6092\left([\mathrm{M}+\mathrm{Na}]^{+}\right.$(calcd. for $^{-}$ $\mathrm{C}_{42} \mathrm{H}_{83} \mathrm{NNaO}_{6}$ 720.6118); (-)-ESI HRMS: $\mathrm{m} / \mathrm{z}=696.6103\left([\mathrm{M}-\mathrm{H}]^{-}\right.$ (calcd. for $\mathrm{C}_{42} \mathrm{H}_{82} \mathrm{NO}_{6} 696.6142$ ). For the formula, see Fig. $\mathbf{S 1}$ in the Supporting Information.

\section{Supporting information}

Spectral data of compounds 1, 3, 8 and $\mathbf{9}$ are available as Supporting Information.

\section{Acknowledgments}

We thank Dr. H. Frauendorf and Dr. M. John for MS and NMR measurements, respectively.

\section{Conflict of Interest}

The authors declare that they have no conflict of interest.

\section{References}

[1] D'Arcy WC. Flora de Panama. Check list and index, Part 1. Saint Louis, MO: Missouri Botanical Garden; 1987: 672

[2] Schultes RE, Raffauf RF. The healing forest: Medicinal and toxic plants of the North West Amazonia. Portland, OR: Dioscorides Press; 1990

[3] Pereira C, Barreto Júnior CB, Kuster RM, Simas NK, Sakuragui CM, Porzel A, Wessjohann L. Flavonoids and neolignan glucoside from Guarea macrophylla. Quim Nova 2012; 35: 1123-1126

[4] Oga S, Sertie JA, Brasile AC, Hanada S. Anti-inflammatory effect of a crude extract from Guarea guidonia. Planta Med 1981; 42: 310-312

[5] Weniger B, Robledo S, Arango G], Deharo E, Aragón R, Muñoz V, Callapa J, Lobstein A, Anton R. Antiprotozoal activities of Colombian plants. J Ethnopharmacol 2001; 78: 193-200

[6] Simoni IC, Munford V, Felicio JD, Lins AP. Antiviral activity of crude extracts of Guarea guidonia. Braz J Med Biol Res 1996; 29: 647-650

[7] Garcez FR, Nuñez CV, Garcez WS, Almeida RM, Roque NF. Sesquiterpenes, limonoids and coumarins from the wood bark of Guarea guidonia. Planta Med 1998; 64: 79-80

[8] Akinniyi JA, Connolly JD, Rycroft DS, Sondengam BL, Ifeadike NP. Tetranortriterpenoids and related compounds. Part 25. Two 3,4-secotirucallane derivates and 2'-hydroxyrohitukin from the bark of Guarea cedrata. Canadian J Chem 1980; 58: 1865-1868

[9] Furlan M, Lopes MN, Fernandes JB, Pirani JR. Diterpenes from Guarea trichilioides. Phytochemistry 1996; 41: 1159-1161

[10] Moutoo BS, Jativa C, Tinto WF, Reynolds WF, McLean S. Ecuadorin, a novel tetranortriterpenoid of Guarea kunthiana: Structure elucidation by 2D-NMR spectroscopy. Canadian J Chem 1992; 70: 1260-126

[11] Kubo I, Mataumoto A, Mataumoto T. New insect ecdysis inhibitory limonoid diacetylazadirachtinol isolated from Azadirachta indica (Meliaceae) oil. Tetrahedron 1985; 42: 485-496

[12] Govindachari TR, Sandhya G, Ganesh Raj SP. Azadirachtins H and I: two new tetranortriterpenoids from Azadirachta indica. J Nat Prod 1992; 55: 596-601

[13] Taylor DAH. Azadirachtin: A study in the methodology of structure determination. Tetrahedron 1987; 43: 2779-2787

[14] Bilton JN, Broughton HB, Jones P, Ley SV, Lidert Z, Horgan ED, Rzepa HS, Sheppard RN, Slawin AMZ, Williams DJ. An X-ray crystallographic, mass spectroscopic and NMR study of the limonoid insect antifeedant azadirachtin and related derivatives. Tetrahedron 1987; 43: 28052815

[15] Heasley B. Synthesis of limonoid natural products. Eur J Org Chem 2011; $1: 19-46$

[16] Khatun M, Billah M, Quader MA. Sterols and sterol glucosides from Phyllanthus species. Dhaka Univ J Sci 2012; 60: 5-10 